\title{
Thirty year retrospective evaluation of pneumonia in a bottlenose dolphin Tursiops truncatus population
}

\author{
Stephanie Venn-Watson*, Risa Daniels, Cynthia Smith
}

National Marine Mammal Foundation, San Diego, California 92106, USA

\begin{abstract}
Pneumonia is one of the most common causes of morbidity in bottlenose dolphins Tursiops truncatus. To better understand associations of pneumonia with demographics, microbiology, pathology, and histopathology, a retrospective study on 42 dolphins from the US Navy Marine Mammal Program dolphin population was conducted (1980 to 2010). A total of 21 (50\%) of the dolphins evaluated had pneumonia confirmed by histopathology. Bacterial and fungal pneumonia was present in 42.9 and $28.6 \%$ of cases (9 and 6 cases), respectively, with Staphylococcus aureus as the most common confirmed pathogen (4 cases, $19 \%$ ). Other pathogens identified as the cause of pneumonia were Cryptococcus neoformans, Erysipelothrix rhusiopathiae, Histoplasma capsulatum, parainfluenza virus, Proteus species, Pseudomonas aeruginosa, and Streptococcus zooepidemicus. Neither sex nor age was a predictor of pneumonia. While many of the infections involved disseminated disease, lungs were consistently the most severely affected organs. The present study demonstrates the high susceptibility of dolphins to respiratory infections. Areas that warrant further investigation include eosinophilic pneumonia, chronic infections, co-infections, and metabolic or iron-storage diseases. There is a continuing need to improve the early diagnosis and effective treatment of pneumonia in dolphins.
\end{abstract}

KEY WORDS: Bacteria - Cetacean - Fungus - Histopathology · Respiratory infection . Staphylococcus aureus

Resale or republication not permitted without written consent of the publisher

\section{INTRODUCTION}

Bottlenose dolphins Tursiops truncatus have an upper and lower respiratory anatomy that enables the rapid exchange of large volumes of air, which may put them at increased risk of respiratory infections (Ridgway 1972a). While air exchange in humans is $20 \%$ per breath, consisting mainly of air in the upper airway, dolphins take short and deep breaths with an exchange of 75 to $90 \%$ of the air in the lungs in one-third of a second (Irving et al. 1941, Olsen et al. 1969, Ridgway et al. 1969), enabling deep lung exposure to airborne threats at the marine surface. Further, dolphins do not have upper airway filters or turbinates to filter air.
It is not surprising, therefore, that pneumonia is one of the most common pathologies reported among dolphins (Baker 1992, Gonzales-Viera et al. 2011, Ridgway 1972b, Medway \& Schryver 1973, Sweeney \& Ridgway 1975). Etiologies that have been associated with pneumonia in dolphins include Aeromonas hydrophila (Cusick \& Bullock 1973), Aspergillus fumigatus (Reidarson et al. 1998b), Coccidioides immitis (Reidarson et al. 1998a), Cryptococcus gattii (Miller et al. 2002), Erysipelothrix rhusiopathiae (VennWatson et al. 2008), Halocercus sp. (lungworm) (Woodard et al. 1969), morbillivirus (Lipscomb et al. 1994b), parainfluenza virus (Nollens et al. 2008), Proteus spp. (Venn-Watson et al. 2008), Pseudomonas aeruginosa (Diamond et al. 1979), Staphylococcus 
aureus (Venn-Watson et al. 2008), Streptococcus Group D (Venn-Watson et al. 2008), and Toxoplasma gondii (Inskeep et al. 1990). While fungal, bacterial, and protozoal causes of pneumonia can be easy to detect upon necropsy, underlying risk factors for opportunistic lung infections should be suspected. These factors include primary but undetected viral infections (Venn-Watson et al. 2008), sequelae to other systemic diseases (e.g. embolic pneumonia from remote areas of localized infection), immune suppression (Lipscomb et al. 1994a), primary insult by marine toxins (Van Dolah 2000), exposures to environmental factors characterized by high sporulation and dust, Santa Ana winds in Southern California, significant pollen or fires in Southern California, and construction activity.

The US Navy Marine Mammal Program has housed and cared for bottlenose dolphins in coastal enclosures for 50 yr. Low mortality rates, high annual survival rates, and high neonatal survival rates of dolphins in this population surpass other published data from either managed collections or wild dolphin populations (Venn-Watson et al. 2011b). The Navy is striving to further reduce the risk of morbidity and mortality in its dolphins due to infectious and metabolic diseases, especially those that impact the respiratory, gastrointestinal, renal, and hepatic systems (Venn-Watson et al. 2011a,b, 2012). Lung histopathology and associated demographic and microbiology data collected from dolphins from 1980 to 2010 were reviewed to better understand the importance, characterization, and potential risk factors associated with pneumonia in dolphins.

\section{MATERIALS AND METHODS}

Navy dolphins are housed in open-ocean netted enclosures in San Diego Bay, CA, USA. They are fed a variety of quality-controlled, previously frozen thawed fish, including mackerel, capelin, herring, and squid, on a kilocalorie per body weight basis. In addition to fish, dolphins are provided daily vitamin supplements and quarterly anthelmintics.

\section{Histopathology and microbiology}

Fresh carcass necropsies, using a standardized protocol, are performed on all dolphins at time of death. A total of 2 to 3 lung samples, as well as samples representative of gross lesions, were collected from 42 dolphins according to the Navy's standard necropsy protocol. The tissue samples were fixed in $10 \%$ neutral buffered formalin for a minimum of $48 \mathrm{~h}$, processed by conventional histologic protocols, and embedded in paraffin. Sections from each block were cut at 5 to $6 \mu \mathrm{m}$ and stained with hematoxylin and eosin. Slides were analyzed with a light microscope by pathologists at reference laboratories. For microbiology, representative fresh tissue was collected during the necropsy and placed in sterile saline. Samples were stored at $4^{\circ} \mathrm{C}$ and shipped to the reference laboratory. Samples were plated on blood agar for both aerobic and anaerobic cultures within $48 \mathrm{~h}$ of collection and held for 10 and $4 \mathrm{~d}$, respectively. Sabouraud agar was used for fungal culture, and plates were held for $30 \mathrm{~d}$. Virus isolation and molecular characterization of Parainfluenza sp. was performed as previously described (Nollens et al. 2008).

\section{Data mining}

Histopathological reports by pathologists on 42 Navy dolphins from 1980 to 2010 were reviewed for evaluation and comments related to lung tissue, including normal findings. An electronic form was used to standardize lung pathologies. Form fields included the presence or absence of pneumonia as well as alveolar proteinosis, angiomatosis, anthracosilicosis, bronchiole mineralization, bronchitis, emphysema, fibrosis (interstitial or pleural), focal pulmonary cysts, hemosiderosis, lymphangitis, nodules or granulomas, pleuritis, pneumocyte hyperplasia, and vasculitis/arteritis. Dolphins with pneumonia diagnosed by histopathology were further characterized by the presence or absence of the following descriptors: bacteria present, bronchopneumonia, eosinophilic, fibrinosuppurative, fungal hyphae present, granulomatous, histiocytic, lymphoplasmacytic, necrotizing, neutrophilic, pyogranulomatous, and ulcerative. Cases of pneumonia were divided according to known or unknown etiology. Microbiology data were matched with histopathological findings, enabling a list of confirmed lungassociated pathogens. Demographics included the age of dolphin at death and sex.

\section{Statistical analyses}

All of the statistical tests were run using SAS version 9.2. Descriptive statistics of the histopathology descriptors provided in the previous section were 
analyzed. Chi square analyses were conducted to compare sex distributions among dolphins with or without pneumonia. Ages were compared using a Kruskal-Wallis test among dolphins that did and did not have pneumonia. Significance for all analyses was defined as a p-value $<0.05$.

\section{RESULTS}

\section{Descriptive statistics}

Of the 42 dolphins evaluated from 1980 to 2010, 28 (66.7\%) had abnormal lung tissue reported by a pathologist (Table 1). The most common abnormal finding was pneumonia ( $50 \%$ of all dolphins examined and $75 \%$ of those with abnormal lung tissue). A total of $42.9 \%$ pneumonia cases had bacteria present,

Table 1. Tursiops truncatus. Frequency of lung histopathology descriptors from 42 bottlenose dolphins (1980-2010)

\begin{tabular}{|c|c|c|c|}
\hline $\begin{array}{l}\text { Lung histo- } \\
\text { pathology } \\
\text { finding }\end{array}$ & $\begin{array}{l}\% \text { of all } \\
\text { dolphins } \\
\text { examined } \\
(\mathrm{n}=42)\end{array}$ & $\begin{array}{l}\% \text { of abnor- } \\
\text { mal lung } \\
\text { tissue cases } \\
(\mathrm{n}=28)\end{array}$ & $\begin{array}{c}\% \text { of } \\
\text { pneumo- } \\
\text { nia cases } \\
(\mathrm{n}=21)\end{array}$ \\
\hline Pneumonia & 50 & 75 & - \\
\hline Eosinophilic & 11.9 & 17.9 & 23.8 \\
\hline Neutrophilic & 11.9 & 17.9 & 23.8 \\
\hline Histiocytic & 21.4 & 32.1 & 42.9 \\
\hline Lymphoplasmacytic & 11.9 & 17.9 & 23.8 \\
\hline Necrotizing & 19 & 28.6 & 38.1 \\
\hline Ulcerative & 2.4 & 3.6 & 4.8 \\
\hline Fibrinosuppurative & 9.5 & 14.3 & 19 \\
\hline Granulomatous & 7.1 & 10.7 & 14.3 \\
\hline Pyogranulomatous & 2.4 & 3.6 & 4.8 \\
\hline Fungal hyphae present & 14.3 & 21.4 & 28.6 \\
\hline Bacteria present & 21.4 & 32.1 & 42.9 \\
\hline Bronchopneumonia & 14.3 & 21.4 & 28.6 \\
\hline Fibrosis & 9.5 & 14.3 & - \\
\hline $\begin{array}{l}\text { Interstitial pulmonary } \\
\text { fibrosis }\end{array}$ & 4.8 & 7.1 & - \\
\hline Pleural fibrosis & 7.1 & 10.7 & - \\
\hline $\begin{array}{l}\text { Fibrous nodule/granu- } \\
\text { lomawith mineralizatior }\end{array}$ & on 7.1 & 10.7 & - \\
\hline Pleuritis & 7.1 & 10.7 & - \\
\hline Alveolar proteinosis & 4.8 & 7.1 & - \\
\hline Angiomatosis & 4.8 & 7.1 & - \\
\hline Bronchitis & 4.8 & 7.1 & - \\
\hline Pneumocyte hyperplasia & 4.8 & 7.1 & \\
\hline Vasculitis/arteritis & 4.8 & 7.1 & - \\
\hline Anthracosilicosis & 2.4 & 3.6 & - \\
\hline Bronchiole mineralization & n 2.4 & 3.6 & - \\
\hline Emphysema & 2.4 & 3.6 & - \\
\hline Focal pulmonary cysts & 2.4 & 3.6 & - \\
\hline Hemosiderosis & 2.4 & 3.6 & - \\
\hline Lymphangitis & 2.4 & 3.6 & - \\
\hline
\end{tabular}

and $28.6 \%$ had fungal hyphae visible by microscopy. Among the pneumonia cases, the most common descriptor was histiocytic, accounting for almost half $(42.9 \%)$. A total of $24 \%$ pneumonia cases were characterized as having eosinophilic, neutrophilic, or lymphoplasmacytic infiltrates. Pneumonia-associated pathogens confirmed by microscopy and culture included Staphylococcus aureus $(\mathrm{n}=4)$, Cryptococcus neoformans $(\mathrm{n}=2)$, Pseudomonas aeruginosa ( $\mathrm{n}=2)$, Erysipelothrix rhusiopathiae, Histoplasma capsulatum, parainfluenza virus, and mixed Proteus species (Table 2).

Other pathologic changes, not necessarily associated with pneumonia, included fibrosis $(\mathrm{n}=4)$, pleuritis $(\mathrm{n}=3)$, and pneumocyte hyperplasia $(\mathrm{n}=2)$ (Table 2). Single cases of bronchiole mineralization, emphysema, focal pulmonary cysts, hemosiderosis, and lymphangitis were also identified.

\section{Comparisons of pneumonia cases and controls}

There were no differences in the presence of pneumonia at death based upon sex or age; 30 and $53.9 \%$ of dolphins with and without pneumonia were female, respectively $(p=0.17)$. The mean ages at death of dolphins with and without pneumonia were 21.4 and $24.1 \mathrm{yr}$, respectively $(\mathrm{p}=0.51)$.

\section{DISCUSSION}

Consistent with findings from wild and other managed dolphin populations (Baker 1992, GonzalesViera et al. 2011, Medway \& Schryver 1973, Sweeney \& Ridgway 1975), we report a high prevalence $(50 \%)$ of pneumonia at death among dolphins. The Navy has a long-standing preventive medicine program for its marine mammals, including routine prophylactic use of antiparasitics, a high quality, previously frozen thawed fish diet, routine physical examinations by veterinarians, daily medical checks, and daily supplements. Additionally, Navy marine mammals receive care from a team of veterinarians using diagnostic tools including blood panels, microbial cultures, molecular diagnostics, urinalyses, ultrasonography, endoscopy, radiography, and computed tomography. The Navy dolphin population has low mortality rates ( 2 to $3 \% \mathrm{yr}^{-1}$ ), high annual survival rates (0.99), and a population with 5 to $10 \%$ of dolphins over $40 \mathrm{yr}$ old (Venn-Watson et al. 2011a). While mortality rates are low in this population, pneumonia continues to be a 
Table 2. Tursiops truncatus. Microbiologically and histopathologically confirmed cases of pneumonia among a population of bottlenose dolphins

\begin{tabular}{|lclll|}
\hline ID & Age (yr) & Sex & Pneumonia pathogen & Cause of death \\
\hline A & 45.4 & M & Cryptococcus neoformans & Disseminated fungal infection \\
B & 28.1 & M & Pseudomonas aeruginosa & Bacterial pneumonia \\
C & 17.7 & F & Staphylococcus aureus & Bacterial pneumonia \\
D & 28.8 & M & Streptococcus zooepidemicus & Disseminated bacterial infection \\
E & 42.2 & $\mathrm{M}$ & Proteus (mixed species) & Disseminated bacterial infection \\
F & 17.7 & M & Cryptococcus neoformans & Disseminated fungal infection \\
G & 28.1 & $\mathrm{M}$ & Unknown & Bronchopneumonia \\
$\mathrm{H}$ & 18.7 & $\mathrm{M}$ & Parainfluenza virus & Viral pneumonia \\
$\mathrm{I}$ & 38.1 & $\mathrm{M}$ & Staphylococcus aureus & Disseminated bacterial infection \\
$\mathrm{J}$ & 7.6 & $\mathrm{~F}$ & Pseudomonas aeruginosa & Bacterial pneumonia \\
$\mathrm{K}$ & 10.1 & $\mathrm{~F}$ & Staphylococcus aureus & Disseminated bacterial infection \\
$\mathrm{L}$ & 5.2 & $\mathrm{M}$ & Mixed bacteria & Bacterial pneumonia \\
$\mathrm{M}$ & 21.4 & $\mathrm{~F}$ & Brucella (suspect) & Staphylococcus septicemia \\
$\mathrm{N}$ & 14.3 & $\mathrm{~F}$ & Unknown & Acute bacterial lung infection \\
$\mathrm{O}$ & 35.2 & $\mathrm{~F}$ & Histoplasma & Disseminated fungal infection \\
$\mathrm{P}$ & 10.1 & $\mathrm{M}$ & Erysipelothrix rhusiopathiae & Disseminated bacterial infection \\
$\mathrm{Q}$ & 9.3 & $\mathrm{M}$ & Staphylococcus aureus & Disseminated bacterial infection \\
$\mathrm{R}$ & 19.6 & $\mathrm{M}$ & Unknown & Pneumonia and suspect septicemia \\
$\mathrm{S}$ & 12.2 & $\mathrm{M}$ & Pseudomonas aeruginosa & Bacterial pneumonia \\
$\mathrm{T}$ & 18.9 & $\mathrm{M}$ & Unknown & Chronic polyserositis and pleuritis \\
\hline
\end{tabular}

common finding at death, supporting the hypothesis that these organisms are particularly susceptible to lower respiratory infections.

Of the dolphins with pneumonia in the present study, nearly half had histiocytic pneumonia. Histiocytes are part of the reticuloendothelial system (mononuclear phagocyte system) and are fixed macrophages in connective tissue (Jansen 1996). Categorical causes of histiocytic lung lesions include neoplasms, proliferative/inflammatory lesions (nodular, diffuse, or mixed), and lesions of uncertain histogenesis (Wang \& Colby 2007). Histiocytic disorders in the lung can be primary or secondary, and finding the etiopathogenesis of primary histiocytic disorders is considered an intriguing research area that is still in flux (Nagarjun et al. 2010).

In general, pathologists in the present retrospective study characterized histiocytic infiltrates as diffuse. Among humans, causes of diffuse histiocytosis in the lung include respiratory bronchiolitis, desquamative interstitial pneumonia, alveolar hemorrhage, eosinophilic pneumonia, drug reaction, infection, obstructive pneumonia, aspiration of exogenous lipid, metabolic or storage diseases, and cobalt scarring (Wang \& Colby 2007). In the present study, $24 \%$ of the pneumonia cases had eosinophilic pneumonia, and it is assumed that all dolphins with known infections received antibacterial treatment with or without antifungal medications. Previous publications including this population of dolphins have discussed metabolic diseases, including insulin resistance, fatty liver disease, and iron overload (Venn-Watson et al. 2011a, 2012). To better understand the cause of pneumonias in dolphins, warranted future studies include standardized re-review and characterization, based on location, severity, and distribution, of dolphin lung tissue and histiocytes by a single pathologist and immunohistochemical staining for antibodies specific to histiocytes, including CD68 and lysozyme (Wang \& Colby 2007).

In the present study, we report associations of pneumonia in dolphins with Staphylococcus aureus, Cryptococcus neoformans, Pseudomonas aeruginosa, Erysipelothrix rhusiopathiae, Histoplasma capsulatum, parainfluenza virus, and mixed Proteus species, most of which have been previously reported as cases in the literature (Miller et al. 2002, Nollens et al. 2008, Venn-Watson et al. 2008). Other known infectious causes of pneumonia in bottlenose dolphins include Aeromonas hydrophila (Cusick \& Bullock 1973), Aspergillus fumigatus (Reidarson et al. 1998b), Coccidioides immitis (Reidarson et al. 1998a), Halocercus sp. (lungworm) (Woodard et al. 1969), morbillivirus (Lipscomb et al. 1994b), Streptococcus Group D (Venn-Watson et al. 2008), and Toxoplasma gondii (Inskeep et al. 1990). In many cases, the cause of death was disseminated bacterial or fungal infections, but the lungs were consistently the most severely affected organ system. There remains a need to assess how often pneumonia is the primary disease, leading to disseminated infections, versus 
when infection has initiated elsewhere in the body and secondarily seeds the lungs.

While many bacterial, fungal, and parasitic pathogens are relatively easy to diagnose postmortem, there is a need to improve pathogen diagnostics early in the course of disease, when treatment is most likely to succeed. Fine needle aspirates and bronchiolar lavage are currently the most successful means of isolating sole bacterial pathogens in marine mammals antemortem (Venn-Watson et al. 2008). While these techniques are useful, they are invasive, can have limited diagnostic value, and involve highly skilled veterinarians working on a calm animal. Diagnostic imaging is a non-invasive means to detect disease, and there is a need to make better use of ultrasound and radiography to find pneumonia early; these techniques may be limited, however, in wild dolphins and for determining the cause of pneumonia. To improve the broad screening of inflammation and pathogens in lungs, alternate, non-invasive methods being investigated by the Navy and collaborators include analyses of volatile organic compounds and condensates in breath (S. Ridgway and L. Yeates pers. comm.).

Pathogens were not found in all of the dolphins with pneumonia in the present study, and it is likely that there are more pathogen discoveries to be made. Etiologies that would not have been detected using the methods described include viruses that do not leave a typical histopathological footprint (e.g. foamy macrophages and inclusion bodies), viruses that were present in the early stage of disease but were gone at the time of death, Mycobacterium, Мycoplasma, Ureaplasma, and Coxiella species, and poor air quality, pollen, and airborne molds that may have initiated or exacerbated pneumonia. Further, some pathogens, such as Brucella, would not have been included in marine mammal microbial diagnostics during the 1980s and early 1990s. Full evaluation, including polymerase catalyzed reaction (PCR) assays and immunohistochemical staining for such pathogens, should be included for cases in which the etiology is unknown or underlying or mixed infection is suspected.

Acknowledgements. The authors thank the many veterinarians, pathologists, and veterinary technicians, including E. Jensen, W. Van Bonn, and S. Ridgway, who helped with the care and necropsies of animals in the present study. We also thank the reviewers who provided valued insight for this manuscript. This study was kindly supported by the US Navy Marine Mammal Program, Biosciences Division, Space and Naval Warfare Systems Center Pacific and the Office of Naval Research, Grant No. N0001411WX20241.

\section{LITERATURE CITED}

Baker JR (1992) Causes of mortality and parasites and incidental lesions in dolphins and whales from British waters. Vet Rec 130:569-572

Cusick PK, Bullock BC (1973) Ulcerative dermatitis and pneumonia associated with Aeromonas hydrophila infection in the bottlenose dolphin. J Am Vet Med Assoc 163:578-579

$>$ Diamond SS, Ewing DE, Cadwell GA (1979) Fatal bronchopneumonia and dermatitis caused by Pseudomonas aeruginosa in an Atlantic bottle-nosed dolphin. J Am Vet Med Assoc 175:984-987

Gonzalez-Viera O, Chavera A, Yaipen-Llanos C, PeralesCamacho R (2011) Histopathological aspects and etiology of pneumonias in stranded marine mammals from Lima, Peru. Braz J Vet Pathol 4:23-29

Inskeep W II, Gardiner CH, Harris RK, Dubey JP, Goldston RT (1990) Toxoplasmosis in Atlantic bottle-nosed dolphins (Tursiops truncatus). J Wildl Dis 26:377-382

Irving L, Scholander PF, Grinnell SW (1941) The respiration of the porpoise, Tursiops truncatus. J Cell Comp Physiol 17:145-168

Jansen HM (1996) The role of alveolar macrophages and dendritic cells in allergic airway sensitization. Allergy 51:279-292

- Lipscomb TP, Kennedy S, Moffett D, Ford BK (1994a) Morbilliviral disease in an Atlantic bottlenose dolphin (Tursiops truncatus) from the Gulf of Mexico. J Wildl Dis 30: 572-576

Lipscomb TP, Schulman FY, Moffet D, Kennedy S (1994b) Morbilliviral disease in Atlantic bottlenose dolphins (Tursiops truncatus) from the 1987-1988 epizootic. J Wildl Dis 30:567-571

Medway W, Schryver HF (1973) Respiratory problems in captive small cetaceans. J Am Vet Med Assoc 163:571-573

Miller WG, Padhye AA, Van Bonn W, Jensen J, Brandt ME, Ridgway SH (2002) Cryptococcosis in a bottlenose dolphin (Tursiops truncatus) caused by Cryptococcus neoformans var. gattii. J Clin Microbiol 40:721-724

Nagarjun RR, Moran CA, Suster S (2010) Histiocytic disorders of the lung. Adv Anat Pathol 17:12-22

> Nollens HH, Wellehan JFX, Saliki JT, Caseltine SL, Jensen ED, Van Bonn W, Venn-Watson S (2008) Characterization of a parainfluenza virus isolated from a bottlenose dolphin (Tursiops truncatus). Vet Microbiol 128:231-242

> Olsen CR, Hale FC, Elsner R (1969) Mechanics of ventilation in the pilot whale. Respir Physiol 7:137-149

Reidarson TH, Griner LA, Pappagianis D, McBain J (1998a) Coccidiomycosis in a bottlenose dolphin. J Wildl Dis 34: 629-631

Reidarson TH, Harrell JH, Rinaldi MG, McBain J (1998b) Bronchoscopic and serologic diagnosis of Aspergillus fumigatus pulmonary infection in a bottlenose dolphin (Tursiops truncatus). J Zoo Wildl Med 29:451-455

Ridgway SH (ed) (1972a) Respiration system. In: Mammals of the sea: biology and medicine. Charles C. Thomas, Springfield, IL, p 260-264

Ridgway SH (ed) (1972b) Diseases: a tabulation of known marine mammal diseases. In: Mammals of the sea: biology and medicine. Charles C. Thomas, Springfield, IL, p 702-704

> Ridgway SH, Scronce BL, Kanwisher J (1969) Respiration and deep diving in the bottlenose porpoise. Science 166: 1651-1654 
Sweeney JC, Ridgway SH (1975) Common diseases of small cetaceans. J Am Vet Med Assoc 167:533-540

- Van Dolah FM (2000) Marine algal toxins: origins, health effects, and their increased occurrence. Environ Health Perspect 108:133-141

Venn-Watson SK, Smith CR, Jensen ED (2008) Primary bacterial pathogens in bottlenose dolphins Tursiops truncatus: needles in haystacks of commensal and environmental microbes. Dis Aquat Org 79:87-93

> Venn-Watson S, Carlin K, Ridgway S (2011a) Dolphins as animal models for type 2 diabetes: sustained, postprandial hyperglycemia and hyperinsulinemia. Gen Comp Endocrinol 170:193-199

Editorial responsibility: Michael Moore, Woods Hole, Massachusetts, USA
Venn-Watson SK, Jensen ED, Ridgway SH (2011b) Population health indicators of the Navy Marine Mammal Program bottlenose dolphin (Tursiops truncatus) population, 1988-2007. J Am Vet Med Assoc 238:356-360

Venn-Watson S, Benham C, Carlin K, St. Leger J (2012) Hemochromatosis and fatty change: building evidence for insulin resistance in bottlenose dolphins (Tursiops truncatus). J Zoo Wildl Med (in press)

> Wang CW, Colby TV (2007) Histiocytic lesions and proliferations in the lung. Semin Diagn Pathol 24:162-182

Woodard JC, Zam SG, Caldwell DK, Caldwell MC (1969) Some parasitic diseases of dolphins. Vet Pathol 6: 257-272

Submitted: December 12, 2011; Accepted: March 22, 2012 Proofs received from author(s): June 14, 2012 